\section{FRI0159 LONGSTANDING ACTIVE GIANT CELL ARTERITIS (GCA) TREATED WITH INFLIXIMAB: REPORT OF FOUR CASESINFLIXIMAB}

${ }^{1} \mathrm{~F}$ Cantini, ${ }^{1} \mathrm{~L}$ Niccoli, ${ }^{2} \mathrm{C}$ Salvarani, ${ }^{2} \mathrm{~L}$ Boiardi, ${ }^{3}$ O Olivieri, ${ }^{3} \mathrm{~A}$ Padula. ${ }^{1 / l}$ Division of Internal Medicine-Rheumatology Unit, Hospital of Prato, Prato; ${ }^{2}$ Division of Rheumatology, Hospital of Reggio Emilia, Reggio Emilia; ${ }^{3}$ Division of Rheumatology, Hospital of Potenza, Potenza, Italy

10.1136/annrheumdis-2001.219

Background TNF-alpha was demonstrated in up to $60 \%$ of the cells in all areas of inflamed arteries of patients with GCA, suggesting a primary role in the inflammatory process. Infliximab, a chimeric monoclonal anti-TNF-alpha, demonstrated remarkable efficacy and safety in the treatment of several rheumatic conditions associated with a chronic inflammatory response.

Objectives To date, no data are available on the therapeutic employment of infliximab in patients with GCA.

The aim of this study was to evaluate the efficacy of infliximab infusions in longstanding, still requiring corticosteroids (CS) GCA.

Methods Four patients (3F,1M; median age:75 ys.) with longstanding (median disease duration: 4 ys.), biopsy proven, active GCA, still requiring CS and whose disease course hab been complicated by serious CS-related adverse events, were scheduled to receive 3 infusions of infliximab $(3 \mathrm{mg} / \mathrm{Kg})$ at weeks 0,2 and 6 . If a clinical and humoral remission was obtained, CS were withdrawn after the 2nd infusion.

Results Three patients had a complete remission of clinical signs/ symptoms and normalisation of ESR and CRP after the 2nd infusion. The remission persisted after the 3rd infusion and over the follow-up (7, 6 and 6 months, respectively).

The fourth patient did not respond to therapy and withdrew from the study after the 2 nd infusion. Infliximab was well tolerated without any side-effects.

Conclusion Our encouraging results suggest that TNF-alpha blockade may represent a valid alternative therapeutic approach to longstanding GCA, still requiring CS and complicated by severe adverse events. The small number of patients and the open study design do not allow conclusive considerations.

\section{FRI0160 CHEMOKINE AND CYTOKINE PROFILE IN SYSTEMIC VASCULITIDES}

L Magrini, F Conti, FR Spinelli, M Bombardieri, G Borsetti, MD Cipriani, C Alessandri, G Valesini. Divisione Di Reumatologia, Policlinico Umberto I, Università Di Roma "La Sapienza", Rome, Italy

\subsection{6/annrheumdis-2001.220}

Background Systemic vasculitides include a heterogeneous group of clinical syndromes characterised by inflammation and necrosis of blood vessel walls. Any type of vessels throughout the body may be involved with protean clinical manifestations, and pathogenetic mechanisms remain mainly unknown.

Objectives Aim of our study was to test the hypothesis that chemokines, cytokines, and eosinophilic inflammation markers could be involved in systemic vasculitides pathogenetic process.

Methods We studied 19 patients with systemic vasculitides diagnosed according to ACR 1990 criteria: 7 pts. with Churg-Strauss vasculitide (CS), 7 pts. with Wegener's Granulomatosis (GW), 5 pts. with Panarteritis Nodosa (PAN) and 24 normal healthy subjects (NHS) as controls. Serum levels of the following mediators: macrophage inflammatory protein $1 \alpha$ (MIP1 $\alpha)$, monocyte chemotactic protein 1 (MCP1), RANTES, interleukin 5 (IL5), granulocyte macrophage-colony stimulating factor (GM-CSF) and eosinophil cationic protein (ECP) were tested by ELISA. For the statistical analysis U-Mann Whitney test has been used.

Results Among chemokines, serum levels of MCP1and RANTES were significantly higher in systemic vasculitides than NHS $(\mathrm{p}<$ 0.001 and $\mathrm{p}<0.007$ respectively), while no differences were demonstrated in MIP1 $\alpha$ serum levels. Regarding cytokines studied, IL5 and GM-CSF serum levels were significantly higher in systemic vasculitides than NHS $(\mathrm{p}<0.001)$. Also ECP serum levels resulted increased in systemic vasculitides than NHS $(\mathrm{p}<$ 0.04) with a significative correlation between ECP levels and blood eosinophilia in vasculitides patients. Furthermore, a specific subgroup analysis showed that serum levels of RANTES, IL5, and ECP resulted increased mainly in CS and GW, while MCP1 and GM-CSF mainly in CS and PAN.

Conclusion Our study demonstrate the increased production of chemokines and cytokines in systemic vasculitides patients. Moreover, the finding of higher ECP serum levels in our patients induce us to hypothesise that eosinophils are actively involved in vasculitides etiopathogenesis.

\section{REFERENCES}

1 Nowack $R$, et al. New developments in pathogenesis of systemic vasculitis. Curr Opin Rheumatol. 1998;10:3-11

2 Priori $R$, et al. Churg-Strauss syndrome during pregnancy after steroid withdrawal. Lancet 1998;352:1599-600

\section{FRI0161 HUMORAL AND CELL-MEDIATED IMMUNE RESPONSE TO COW'S MILK PROTEINS IN BEHÇET'S DISEASE}

G Triolo, A Accardo-Palumbo, F Ciccia, A Ferrante, C Mantione, E Giardina, G Licata. Department of Internal Medicine, Section of Rheumatology, University, Palermo, Italy

\subsection{6/annrheumdis-2001.221}

Background Behçet's disease (BD) is a multisystemic inflammatory disease characterised by a number of immunological variables. The relevance of these findings is not sufficient to support an autoimmune pathogenesis. Consumption of cow's milk proteins might be a risk factor for the development of autoimmune disease.

Objectives To investigate the humoral and cell-mediated immune response against cow's milk proteins in BD.

Methods Sera from 47 patients with BD and 38 healthy subjects were studied. Anti beta-casein (bC) and anti beta-lactoglobulin (bLG) antibodies were detected by ELISA. Peripheral blood mononuclear cells from 16 BD patients and from 8 healthy controls were cultured in the presence of PHA, beta-casein or betalactoglobulin and IL-4 and Interferon-gamma measured in the culture supernatants by ELISA.

Results Significant higher levels of anti-bC and anti-bLG were found in the sera of patients with active disease (anti-bCIgA:1.89 \pm 2.2 SDU;-IgG:3.64 \pm 5.93; anti-bLG-IgA:2.07 \pm 2.51;-IgG:1.72 \pm 2.7 ) compared with those of inactive patients (anti-bC-IgA:0.68 \pm 0.92;-IgG:0.83 \pm 1.26; anti-bLG-IgA:0.70 \pm 1.12;-IgG:0.37 \pm 0.65 ) or controls. Higher levels of IFNgamma but not IL-4 were found in the supernatants of active patient cultures but not in those of patients with inactive disease or controls in both bC and bLG studies. Levels were comparable to those obtained with PHA.

Conclusion The occurrence of anti-bC and anti-bLG in BD and studies on the cellular immune response with Th1 cytokine secretion might further support the putative role of cow's milk 
protein immune response in the pathogenesis of autoimmune disease and in particular of BD.

\section{FRI0162 CLINICAL FEATURES OF A SET OF PATIENTS WITH ANTI- NEUTROPHIL CYTOPLASMIC ANTIBODIES}

EG Tomero Muriel, G García-Melcón, R Velayos, AM Ortiz, I González-Alvaro. Rheumatology, Hospital de La Princesa, Madrid, Spain

\subsection{6/annrheumdis-2001.222}

\section{Background}

Objectives To analyse characteristics and clinical features of patients with positive antineutrophil cytoplasmic antibodies (ANCA).

Methods Retrospectively we reviewed 71 patients tested for the presence of ANCA using indirect inmunofluorescence (IFF; ptterns pANCA and cANCA) and/or antimieloperoxidase ELISA (aMPO) from 1993 to 1999. The variables observed were age, sex, origin department, clinical manifestations, final diagnosis, disease evolution and treatment.

Results Mean age was 60.2 years (16-97) being women $63.3 \%$. cANCA was positively tested in $42 \%$ of patients and pANCA in 58\%(59\% aMPO). The distribution among departments was: Internal Medicine 22.5\%, Rheumatology 22.5\%, Nephrology 16.5\%, Pneumology 14.9\%, Gastroenterology $13.5 \%$ and Dermatology 12\%. 28 patients suffered from lung affections, 27 had kidney affections (30\% rapidly progressing glomerulonephritis), 18 skin involvement, 19 musculoesqueletal manifestations, 5 hearts affections, 3 neuropathies and 2 eye involvement. Diagnosis were: 5 Wegeners Granulomatosis, 5 Microscopic polyangiitis, 8 pANCA associated vasculities, 4 leucocytoclastic vasculitis, 7 rheumatoid arthritis, 7 inflammatory bowel diseases, 6 systemic inmunolopathologycal diseases, 21 not autoimmune disorders and 8 without final diagnosis. Progress: 42\% suffered from periodical relapses, 28\% without clinical manifestations, 21\% died. $53 \%$ of death were directly caused by ANCA associated vasculitis, $26 \%$ were due to concomitant infections and the rest were caused by non related complications.

Conclusion 1. Despitethe high percentage of detected cANCA by IIF only Wegeners granulomatosis were diagnosed, so the use of ELISA antiproteinase-3 must be used. 2. It was observed a high mortality rate in patients in patients with positive ANCA.

\section{FRI0163 INITIAL ASSESSMENT OF WEGENER'S GRANULOMATOSIS - AN AUDIT OF RHEUMATOLOGICAL PRACTICE}

JS McLaren, RA Luqmani. Rheumatic Diseases Unit, Western General Hospital, Edinburgh, UK

\subsection{6/annrheumdis-2001.223}

Background Accurate initial assessment of organ involvement in Wegener's granulomatosis (WG) is essential to determine immediate and future management. Renal and pulmonary involvement are associated with a worse outcome.

Objectives We audited the initial assessment of patients referred to the Rheumatic Diseases Unit (RDU) who were subsequently confirmed to have WG. As there are no published gold standards on what should be assessed, the following essential items were chosen following consensus discussion: blood pressure (BP), urinalysis (and microscopy if haematuria present) and serum creatinine for renal involvement and chest radiograph (CXR) for pulmonary involvement. Tissue biopsy from symptomatic sites was important to establish evidence of granulomata or inflammation (ear, nose and throat (ENT)), vasculitis (cutaneous/ENT) or focal segmental glomerulonephritis (renal).

Methods All patients with WG referred to the RDU over 8 years until Sept 2000 were identified by search of the computer database. Patients with incomplete medical records and re-referrals were excluded. 35 patients were identified and their medical records and CXRs were reviewed to establish if basic investigations had been performed and if so, their results.

Results Demographics: 19 F:16 M. Mean age 53, range 13-85. $83 \%$ of patients were referred by either general practitioners, general physicians or ENT surgeons. Features at presentation (\%): ENT (94), arthralgia (66), cutaneous (51), renal (40), ocular (29), pulmonary (20) and neurological (17). The results are presented in the table. In $29 \%(10 / 35)$ of patients at least one test was not performed. 11\% (4/35) of patients had hypertension (diastolic BP > 99) and in none were recommendations made for BP to be rechecked or treatment to be commenced. $6 \%(2 /$ 35 ) of patients with microscopic haematuria did not have urine microscopy or a renal biopsy performed (one patient also had an elevated creatinine). 9 patients had an abnormal CXR: 1 had evidence of previous tuberculosis, 4 had active pulmonary disease and 4 had further investigation to exclude infection.

\begin{tabular}{llllll}
\multicolumn{7}{l}{ Abstract FRI0163 Table 1} \\
\hline & BP & Urine & Creatinine & CXR & Biopsy \\
\hline Test performed (no. of pts) & $33 / 35$ & $33 / 35$ & $31 / 35$ & $31 / 35$ & $30 / 35$ \\
Test performed (\% of pts) & 94 & 94 & 89 & 89 & 86 \\
Test abnormal (\% of pts) & 11 & 46 & 23 & 26 & 87 \\
\hline Initial assessment of Wegener's granulomatosis (pts = patients).
\end{tabular}

Conclusion $71 \%$ of patients referred to a tertiary rheumatology centre and later confirmed to have WG received adequate basic investigation at presentation. Patients found to be hypertensive should have their BP repeated and those with haematuria should have urine microscopy performed. These results indicate that we should be more vigilant in performing basic tests in patients with suspected WG and in this regard our data have been presented to our department by means of an audio visual presentation and written information. The audit will be repeated in 2005 to reassess the recording of basic investigations in patients with WG.

\section{FRI0164 ANTIBODIES TO PROTEINASE-3, MYELOPEROXIDASE AND B2GPI}

${ }^{1} \mathrm{AA}$ Baranov, ${ }^{1} \mathrm{SY}$ Kirdyanov, ${ }^{2} \mathrm{EL}$ Nassonov, ${ }^{2} \mathrm{TV}$ Beketova, ${ }^{1} \mathrm{MS}$ Gurieva, ${ }^{1}$ OV Bashina, ${ }^{1}$ NE Abaytova. Internal Medicine, Medical Academy, Yaroslavl; ${ }^{2}$ Internal Medicine, Medical Academy, Moscow, Russia

\subsection{6/annrheumdis-2001.224}

\section{Background}

Objectives To investigate the relationship between antibodies to proteinase-3 (anti-PR3), myeloperoxidase (anti-MPO) and b2GPI (anti-b2GPI) in patients (pts) with systemic vasculitis and primary antiphospholipid syndrome (PAPS).

Methods The sera from 18 pts with polyarteritis nodosa (PAN), 18 pts with Takayasu's arteritis (TA), 21 pts with thromboangiitis obliterans (TAO), 21 pts with Henoch-Schonlein purpura (HSP), 